\title{
SILAGEM DE RESÍDUOS DA FILETAGEM DE TILÁPIA DO NILO (Oreochromis niloticus), COM ÁCIDO FÓRMICO - ANÁLISE BROMATOLÓGICA, FÍSICO-QUÍMICA E MICROBIOLÓGICA
}

\author{
Silage of tilapia (Oreochromis niloticus) filetage residues with formic acid - \\ Bromatological, phisico-chemical and microbiological analyses \\ Marinez Moraes de Oliveira ${ }^{1}$, Maria Emília de Sousa Gomes Pimenta ${ }^{2}$, \\ Antônio Cléber da Silva Camargo ${ }^{3}$, João Evangelista Fiorini ${ }^{4}$, Carlos JoséPimenta ${ }^{5}$
}

\begin{abstract}
RESUMO
O experimento avaliou o valor nutritivo da silagem ácida da filetagem da tilápia do Nilo (Oreochromis niloticus Linneaus, 1758), visando sua utilização em substituição à farinha de peixe na alimentação de organismo aquático. A silagem consistiu de resíduos da filetagem de tilápia (carcaça) e $3 \%$ de ácido fórmico, armazenada em temperatura ambiente (máxima média de $21,5^{\circ} \mathrm{C}$ ) e temperatura mínima média de $15^{\circ} \mathrm{C}$, por trinta dias, em baldes de polietileno com um orifício, por onde os gases saiam. $\mathrm{O} \mathrm{pH}$ foi monitorado no $1^{\circ}$, $15^{\circ}$ e $30^{\circ}$ dia. Foram realizadas análises microbiológicas para contagem total de microrganismos e coliformes a $35^{\circ} \mathrm{C} \mathrm{e} 45^{\circ} \mathrm{C} . \mathrm{O}^{\mathrm{pH}}$ apresentou média de 3,95 ao final dos 30 dias. Nas análises microbiológicas observou-se a ausência de coliformes a $45^{\circ} \mathrm{C}$ e, que a quantidade de microrganismos diminuiu gradativamente. Do ponto de vista microbiológico, a silagem ácida de resíduo da filetagem de tilápia mostrou-se como alimento alternativo viável para a alimentação animal.
\end{abstract}

Termos para indexação: Silagem, alimentação, resíduos, peixe, filetagem.

\begin{abstract}
The experiment was carried out for evaluate the nutritional value of the silage of Nile tilapia (Oreochromis niloticus Linneaus, 1758) filetage residues with formic acid as a replace of fish meal in aquatic organisms feeding as protein source. The silage consisted of tilapia filetage residues (carcass) and 3\% formic acid, and it was stored in environmental temperature with a maximum average of $21,5^{\circ} \mathrm{C}$ and a minimum average of $15^{\circ} \mathrm{C}$, during thirty days, in polyethylene pails with an orifice for the exhaustion of gases. The $\mathrm{pH}$ was monitored on the $1^{\text {st }}, 15^{\text {th }}$ and $30^{\text {th }}$ day. The microbiological analyses were made for the total count of microorganisms and coliforms at $35^{\circ} \mathrm{C}$ and $45^{\circ} \mathrm{C}$. The average $\mathrm{pH}$ was 3.95 at the end of 30 days. The microbiological analyses showed absence of coliformes at $45^{\circ} \mathrm{C}$ and a gradual reduction in the quantity of microorganisms. From the microbiological standpoint, the acid silage of tilapia residues was shown to be an alternative viable diet for animal feeding.
\end{abstract}

Index terms: Silage, feeding, residues, fish, filetage.

(Recebido para publicação em 19 de abril de 2005 e aprovado em 18 de outubro de 2005)

\section{INTRODUÇÃO}

A aqüicultura é uma das atividades zootécnicas que vêm se destacando no Brasil como alternativa econômica para o pequeno e médio produtor, sendo propícia ao aproveitamento de áreas improdutivas, transformando-as e elevando sua potencialidade e produtividade. Com o avanço tecnológico, o processo de industrialização de pescado vem crescendo de forma constante com o surgimento de indústrias de beneficiamento, que visam o aprimoramento no processo de obtenção de filés.

Um dos grandes problemas deste desenvolvimento está no descarte dos resíduos de peixes que, quando realizado de forma incorreta, constitui problema sanitário e ambiental para os produtores e as indústrias. $\mathrm{O}$ aproveitamento do pescado em forma de filé encontra-se na faixa de $33 \%$, restando em torno de 67\% de resíduos (MARCHI, 1997; RIBEIRO et al., 1998; SOUZA et al., 1999). A silagem ácida de peixe é um produto obtido dos resíduos misturados e moído em meio ácido. As enzimas presentes na matéria-prima separam a proteína e a liquefazem, enquanto o ácido previne a ação dos microrganismos. O produto final é fonte de proteína de alta qualidade e minerais para a alimentação animal. Com a elaboração da silagem de resíduos de peixes podem-se obter vantagens econômicas, além de sanar o problema de descarte de resíduos. Entre as vantagens da produção de silagem em relação às farinhas de pescado, o processo é independente de escala. A elaboração é rápida, com custo razoável, possibilitando a utilização imediata do produto, não sendo necessário seu armazenamento em refrigerador.

\footnotetext{
${ }^{1}$ Mestre em Ciência Animal da UNIFENAS - Rua Alterosa, 89 - 37.953-000 - São José da Barra, MG.

2 Doutora em Nutrição Animal, Professora da Universidade José do Rosário Vellano/UNIFENAS - Cx. P. 23 - $37.130-000$ - Alfenas, MG

${ }^{3}$ Doutor em Zootecnia, Professor da Universidade Federal de Minas Gerais/UFMG - Cx. P. 135 - 39.404-006 - Montes Claros, MG.

${ }^{4}$ Doutor em Microbiologia, Professor da Universidade José do Rosário Vellano/UNIFENAS - Cx. P. 23 - 37.130-000 - Alfenas, MG.

${ }^{5}$ Doutor em Ciência dos Alimentos - Professor da Universidade Federal de Lavras/UFLA - Cx. P. 3037 - $37200-000$ - Lavras, MG.
} 
Objetivou-se com este trabalho a elaboração da silagem ácida de resíduos da filetagem de tilápia do Nilo (Oreochormis niloticus), por meio da adição de ácido fórmico. Avaliou-se a silagem por meio de análises bromatológicas, físico-químicas, microbiológicas e de estabilidade, a fim de subsidiar as pesquisas posteriores, visando a utilização da mesma em substituição à farinha de peixe na alimentação de organismos aquáticos como fonte protéica.

\section{MATERIAL E MÉTODOS}

A elaboração da silagem foi realizada no Laboratório de Reprodução de Peixes da Universidade José do Rosário Vellano, Alfenas - MG. O material consistiu de resíduos de filetagem de tilápia do Nilo (Oreochromis niloticus), constituídos somente da carcaça espinhas (sem nadadeiras, sem cabeça e vísceras), da região da Pousada do Porto Alfenas - MG. Os resíduos foram moídos em máquina elétrica de moer carne. Após homogeneização manual, a massa foi dividida e adicionou-se 3\% de ácido fórmico a 98\%, em relação ao peso do resíduo moído, conforme recomendado por Beraquet \& Galacho (1983) e Tatterson \& Windsor (1974).

A silagem foi armazenada em temperatura ambiente com temperatura máxima média de $21,5^{\circ} \mathrm{C}$ e temperatura mínima média de $15^{\circ} \mathrm{C}$, por trinta dias, em baldes de polietileno com um orifício, por onde os gases saiam, em temperatura ambiente conforme a Tabela 1.

Durante os 30 dias, foram agitados duas vezes ao dia (de manhã e à tarde) para obter-se uniformidade. No $1^{\circ}$ e ao $15^{\circ}$ e $30^{\circ}$ dia após a ensilagem, foram retiradas amostras para análises microbiológicas e bromatológicas. A composição proximal da silagem seca em estufa regulada a $65^{\circ} \mathrm{C}$, realizada no Laboratório de Produtos Vegetais do Departamento de Ciência dos Alimentos, onde foram analisadas a umidade, a proteína bruta, o extrato etéreo e as cinzas, conforme AOAC (1990). A energia bruta foi determinada em bomba calorimétrica no Laboratório de
Nutrição Animal do Departamento de Zootecnia da Universidade Federal de Lavras - MG, conforme metodologia descrita por Matterson (1965).

A medida do $\mathrm{pH}$ foi realizada no Laboratório de Solos da Universidade José do Rosário Vellano, Alfenas - MG, com peagômetro digital no $1^{\circ}, 15^{\circ}$ e $30^{\circ}$ dias. A qualidade microbiológica da silagem foi analisada através de culturas das amostras no Laboratório de Biologia e Fisiologia de Microrganismos da Universidade José do Rosário Vellano, Alfenas - MG. Para a contagem total de microrganismos mesófilos, as amostras foram homogeneizadas em Becker esterilizado com auxílio de pistilo, na proporção de 25 gramas para $225 \mathrm{~mL}$ de água destilada. A partir desta diluição $\left(10^{-1}\right)$ obtiveram-se as diluições decimais em duplicata até $10^{-5}$. Em seguida, foram pipetadas assepticamente alíquotas de 1 $\mathrm{mL}$ e transferidas para placas de Petri devidamente identificadas. Foram semeadas em duplicata, utilizando-se quatro diluições diferentes e adicionado-se a cada placa 30 $\mathrm{mL}$ do meio de cultura Agar Padrão resfriado (PCA), fundido a $55^{\circ} \mathrm{C}$. Em seguida, as placas foram invertidas e incubadas a $35^{\circ} \mathrm{C}$ por 24 horas. Para a contagem de fungos e leveduras, as amostras foram semeadas em duplicata, utilizando-se quatro diluições diferentes e adicionado-se a cada placa 30 $\mathrm{mL}$ do meio de Sabouroud e incubadas a $28^{\circ} \mathrm{C}$ por 72 horas, conforme metodologia descrita no Manual de Sistemática Bacteriana de Bergey's (KRIEG \& HOLT, 1984). Para determinação do número mais provável (NMP) de coliformes totais e fecais, foi utilizada também a metodologia do Manual de Sistemática Bacteriana de Bergey's (KRIEG \& HOLT, 1984), por meio da técnica dos tubos múltiplos com tubos de Durham (três séries de três tubos de cada diluição $10^{-1}$, 10 ${ }^{2}$ e $10^{-3)}$. Empregou-se como meio de cultura, para o teste presuntivo, o caldo lauril-sulfato e a confirmação em caldo verde brilhante, incubação realizada a $35^{\circ} \mathrm{C}$, durante 24 horas. Os coliformes $35^{\circ} \mathrm{C}$ foram pesquisados em tubos contendo caldo $\mathrm{EC}$, com posterior inoculação a $45^{\circ} \mathrm{C}$ durante 24 horas, em banho-maria, com três tubos de cultivo para cada.

TABELA 1 - Temperatura máxima e mínima do ambiente, durante o período de armazenagem da silagem.

\begin{tabular}{ccc}
\hline & \multicolumn{2}{c}{ Temperatura $\left({ }^{\circ} \mathrm{C}\right)$} \\
\hline Dia & Maxima & Mínima \\
\hline $1^{\circ}$ & $18^{\circ} \mathrm{C}$ & $12^{\circ} \mathrm{C}$ \\
$10^{\circ}$ & $23{ }^{\circ} \mathrm{C}$ & $15^{\circ} \mathrm{C}$ \\
$20^{\circ}$ & $23{ }^{\circ} \mathrm{C}$ & $17^{\circ} \mathrm{C}$ \\
$30^{\circ}$ & $22^{\circ} \mathrm{C}$ & $16^{\circ} \mathrm{C}$ \\
Media Final & $21,5^{\circ} \mathrm{C}$ & $15^{\circ} \mathrm{C}$ \\
\hline
\end{tabular}


A estabilidade aeróbia foi realizada no Laboratório de Sementes da Universidade José do Rosário Vellano Campus Alfenas, determinada pela resistência ao aumento da temperatura na massa de silagem segundo a técnica adaptada por Bernardes (2003).

\section{RESULTADOS E DISCUSSÃO}

O material obtido da silagem ácida de resíduos da filetagem de tilápia se liquefaz já nos primeiros dias, sob efeito do ácido fórmico, cuja coloração passou de marrom com tons avermelhados para marrom-claro. Verificou-se que neste processo o ácido substitui a função bioquímica principal dos microrganismos que ocorre durante a fermentação do substrato. Em estudo realizado por Beerli et al. (2004), observou-se que o processo não necessita ser anaeróbio como nas silagens de outros produtos, pois os microrganismos deixam de ter o papel principal nas transformações do material.

A silagem foi elaborada no inverno e, mesmo assim, se liquefez na primeira semana. Os resultados da umidade, proteína bruta, extrato etéreo, cinzas e energia bruta encontram-se na Tabela 2.

A obtenção de silagem com teor mais baixo de umidade é importante para a formulação de rações, visando melhor estabilidade microbiológica do material. Na Tabela 2, pode-se notar que a umidade aumentou muito pouco aos 30 dias do processo de ensilagem. O nível máximo atingido foi de 42,90\% aos 15 dias, diminuindo aos 30 dias (42,09\%).

O valor máximo observado foi $9 \%$ inferior ao relatado por Pereira (2002), o qual trabalhou com silagem biológica, o que pode ser explicado pela utilização do farelo de trigo na confecção da mesma, o que diminuiu a matéria seca. Lessi (2004) também encontrou valores de umidade superiores aos encontrados no presente experimento. Bello (2004), Berenz (2004), Hoffman (1981), Ottati et al. (1990), Tatterson (1982) e Tibbets et al. (1981), encontraram valores inferiores aos relatados por Pereira (2002).

Com relação à proteína bruta, Pereira (2002) observou valor de $29,46 \%$. Os valores encontrados na silagem ora elaborados foram em média $48,30 \%$ de proteína bruta no $30^{\circ}$ dia, indicando ação de proteases endógenas presentes nos tecidos do peixe, aumentando a solubilização da proteína. $\mathrm{O}$ aumento da temperatura na massa com o passar dos dias inativou total ou parcialmente essas enzimas, estabilizando seu valor nutricional.

Comparativamente, a silagem de peixe possui menor teor de proteína bruta que a farinha de peixe, a qual, segundo Pimenta (2001), apresenta teor protéico em torno de $60 \%$. Entretanto, esse alimento apresenta teor protéico alto. O conteúdo de extrato etéreo na matéria prima e na silagem é considerado importante parâmetro de qualidade do produto. Mesmo com o alto teor de lipídio, o que pode prejudicar o processamento e o armazenamento do produto, uma grande vantagem é que, segundo Maia et al. (1998), o óleo da silagem de tilápia pode ser utilizado em substituição ao óleo de soja nas rações, por ser fonte de ácidos graxos poliínsaturados. Uma outra vantagem é que, segundo Ramos et al. (1994), a excessiva solubilização da proteína pode ser reduzida pelos lipídios provenientes da silagem, podendo assim, melhorar sua qualidade. Por outro lado, a presença de óleo, com altos níveis de ácidos graxos poliínsaturados, sujeitos à oxidação, torna a silagem, além de não palatável, imprópria ao consumo do animal.

Vários autores sugeriram a adição de antioxidantes na silagem ácida (BELLO, 2004; BERENZ, 2004; TATTERSON, 1982). Os maiores problemas com a presença de lipídios na silagem estão na fase pós-abertura dos silos e no seu armazenamento, quando a presença de oxigênio do ar acelera a rancidez. No caso da silagem elaborada no presente experimento, o teor de extrato etéreo diminuiu do $1^{\circ}$ (39,8\% de extrato etéreo) até o $30^{\circ}$ dia de ensilagem $(22,32 \%$ de extrato etéreo).

Pereira (2002) encontrou o valor médio de $17,9 \%$ de extrato etéreo, inferior ao relatado no presente trabalho. Outros autores encontraram, também, valores inferiores: 18,40\% (BERMUDEZ et al., 1999), 7,9\% (HOFFMAM, 1981), 5,31\% (BERENZ, 2004), 8,93\% (LESSI, 2004). Estes resultados podem ser explicados pelo tipo de metodologia do processo de ensilagem e/ou pelos diferentes tipos de matéria - prima utilizada. Entretanto, deve ser lembrado que, ao se utilizar a silagem ácida na alimentação animal, deve-se adicionar um agente antioxidante, visando minimizar ou mesmo impedir a oxidação.

Conforme demonstrado na Tabela 2, o teor de cinzas variou e foi superior ao relatado por Pereira (2002). Pode-se constatar que a silagem de peixe obtida apresentou altos teores de minerais, sendo, portanto, boa fonte desses nutrientes. Acredita-se que o resultado em relação às cinzas foi devido à utilização de resíduos das carcaças (sem cabeça e vísceras). A energia bruta da silagem ácida de resíduos da filetagem de tilápia determinada em bomba calorimétrica foi de $3.911 \mathrm{kcal} / \mathrm{kg}$. O mesmo foi superior ao relatado por Braga et al. (1998) para a farinha de peixe $(3.555 \mathrm{kcal} \mathrm{EB} / \mathrm{kg})$, principal fonte protéica das rações para organismos aquáticos. Castro et al. (2001) também encontraram valor inferior de energia bruta (3.611 kcal de EB/kg) para a farinha de peixe. Provavelmente, o valor de energia bruta encontrado seja conseqüência do alto teor de extrato etéreo, pois, no processamento da silagem, não houve o desengorduramento.

Os valores de $\mathrm{pH}$ da silagem ácida de resíduos da filetagem de tilápia do Nilo (Oreochromis niloticus) no $1^{\circ}, 15^{\circ}$ e $30^{\circ}$ dia processo de ensilagem encontram-se na Tabela 3.

Ciênc. agrotec., Lavras, v. 30, n. 6, p. 1218-1223, nov./dez., 2006 
Ao final de 30 dias, o pH apresentou média de 3,95. Em alguns estudos, vários autores concluíram que o valor do pH da silagem estável deva ser inferior a 4,5 (BELLO, 2004; LIEN et al., 2000). Tatterson \& Windsor (1974), utilizando 3\% de ácido fórmico a 98\%, obtiveram seis fórmulas de silagem com diferentes pescados tendo o $\mathrm{pH}$ ficado em torno de 4,0 em todas as fórmulas. Entretanto, Dapkevicius et al. (1998) concluíram que o pH abaixo de 4,5 foi responsável pelo aumento da hidrólise da proteína. Entretanto, segundo esses mesmos autores, o $\mathrm{pH}$ abaixo de 4,5 e as características físicas da silagem de peixe levam a menor concentração de oxigênio dentro do material ensilado e são favoráveis à ação das enzimas aminoácido-descarboxilases de origem endógena, responsáveis pela formação de aminas biogênicas, consideradas risco à saúde do animal.

As análises microbiológicas da silagem ácida de resíduos da filetagem da tilápia do Nilo (Oreochromis niloticus) encontram-se na Tabela 4. No primeiro dia houve crescimento de $1,2 \times 10^{5}$ de bactérias mesófilas/g. Com relação ao número de coliformes totais $\left(35^{\circ} \mathrm{C}\right)$ a estimativa foi $2,4 \times 10^{2} / \mathrm{g}$ de silagem estimadas em NMP. No teste de coliformes fecais a $45^{\circ} \mathrm{C}$, não houve crescimento. Fungos e leveduras registraram um quantitativo de $3 \times 10^{3} \mathrm{UFC} / \mathrm{g}$ de silagem.

As demais análises microbiológicas realizadas durante o experimento não demonstraram crescimento de microrganismos. Baseando-se nas afirmações de Beerli et al. (2004), a contagem total de microrganismos como parâmetro para analisar a qualidade dos alimentos. Observou-se neste estudo que a quantidade de microrganismos diminuiu gradativamente, garantindo assim que a silagem pode trazer benefícios à alimentação animal.

A estabilidade aeróbia da silagem ácida de residuos da filetagem de tilápia do Nilo encontra-se resumida na Tabela 5.

Neste estudo, a estabilidade aeróbia determinada em câmara climática à temperatura de $25^{\circ} \mathrm{C}$ com variação de $\pm 1^{\circ} \mathrm{C}$, mostrou que a silagem estabilizou-se no terceiro dia, assim permanecendo até término ao sexto dia (período adotado para a avaliação).

TABELA 2 - Análises bromatológicas da silagem realizadas durante o período de armazenagem.

\begin{tabular}{lccc}
\hline \multicolumn{1}{c}{ Variável } & $\mathbf{1}^{\mathbf{0}}$ Dia & $\mathbf{1 5}^{\mathbf{0}} \mathbf{D i a}$ & $\mathbf{3 0}^{\mathbf{0}} \mathbf{\text { Dia }}$ \\
\hline Umidade & 40,20 & 42,90 & 42,09 \\
Proteína Bruta & 39,08 & 41,36 & 48,30 \\
Extrato Etéreo & 22,32 & 20,60 & 19,25 \\
Cinzas & 29,60 & 29,50 & 29,38 \\
Energia Bruta & & & 3.911 \\
\hline
\end{tabular}

* com base na matéria seca.

TABELA 3 $-\mathrm{pH}$ da silagem no $1^{\circ}, 15^{\circ}$ e $30^{\circ}$ dias de armazenagem.

\begin{tabular}{cc}
\hline Dia & pH \\
\hline $1^{\circ}$ & 3.63 \\
$15^{\circ}$ & 3.96 \\
$30^{\circ}$ & 4.25 \\
\hline
\end{tabular}

TABELA 4 - Análises Microbiológicas da Silagem Ácida de Resíduos da Filetagem de Tilápia do Nilo (Oreochromis niloticus).

\begin{tabular}{lccc}
\hline \multicolumn{1}{c}{ Variavel } & Contagem & \\
\hline & $\mathbf{1}^{\mathbf{0}} \mathbf{~ d i a}$ & $\mathbf{1 5}^{\mathbf{0}} \mathbf{\text { dia}}$ & $\mathbf{3 0}^{\mathbf{0}} \mathbf{\text { dia}}$ \\
\hline Contagem Total Microrg Mesofilos & $1,2 \times 10^{5} \mathrm{UFC} / \mathrm{g}$ & ausente & Ausente \\
Coliformes Totais $\left(35^{\circ} \mathrm{C}\right)$ & $2,4 \times 10^{2} / \mathrm{g}$ & ausente & Ausente \\
Coliformes Fecais $\left(45^{\circ} \mathrm{C}\right)$ & ausente & ausente & Ausente \\
Fungos e leveduras & $3 \times 10^{3} \mathrm{UFC} / \mathrm{g}$ & ausente & Ausente \\
\hline
\end{tabular}

Ciênc. agrotec., Lavras, v. 30, n. 6, p. 1218-1223, nov./dez., 2006 
TABELA 5 - Estabilidade aeróbia da silagem ácida de resíduos da filetagem de tilápia do Nilo (Oreochromis niloticus).

\begin{tabular}{cc}
\hline Dia & Temperatura $\left({ }^{\circ} \mathbf{C}\right)$ \\
\hline 1 & 19,5 \\
2 & 24,0 \\
3 & 25,0 \\
4 & 25,0 \\
5 & 25,0 \\
6 & 25,0 \\
\hline
\end{tabular}

\section{CONCLUSÕES}

$\mathrm{O}$ experimento realizado permite concluir que a silagem ácida de resíduos da filetagem de tilápia mostra-se como alimento alternativo viável para a alimentação animal; o valor de $\mathrm{pH}$ apresentado reforça a importância de novos estudos avaliando o efeito nocivo à saúde animal no que concerne à formação de aminas biogênicas.

\section{REFERÊNCIAS BIBLIOGRÁFICAS}

ASSOCIATION OF OFFICIALAGRICULTURE CHEMISTS. Official methods of analysis of the Association of Official Agriculture Chemists. Washington, 1990.

BEERLI, E. L.; BEERLI, K. M. C.; LOGATO, P. V. R. Silagem ácida de resíduos de truta (Oncorhynchus wykiss), com a utilização de ácido muriático. Ciência e Agrotecnologia, Lavras, v. 28, n. 1, p. 196-200, 2004.

BELLO, R. A. Experiências com ensilado de pescado en Venezuela. Instituto de Ciências y Tecnologia de Alimentos. Caracas: Universidad Central de Venezuela, 2004. Disponível em: <http//- www.foo.org/livestock/ raphp134/cap1.htmp. Acesso em: 23 out. 2004 .

BERAQUET, N. J.; GALACHO, S. A. A. Composição, estabilidade e alterações na fração protéica e no óleo de ensilados de resíduos de peixe e de camarão. ITAL, São Paulo, v. 13, p. 149-174, 1983.

BERENZ, Z. Utilización del ensilado de residuos de pescado en pollos. Lima: Instituto Tecnológico Pesquero de el Peru, 2004. Disponível em: <ht 'aphp134/cap2.htmi . Acesso em: $19 \mathrm{dez} .2004$.

BERMUDEZ, J. E. et al. Ensilage de vísceras de pescado bacham blanca (Piaractus brachyponum) como fuente de proteína para la alimentación de cerdos de engorde en una dieta com aceite crudo de palma (Elaeis guineesis-Elaeis oloifera). Livestock Reserch for Rural Development, [S.I.], v. 11, n. 2, 1999.

BERNARDES, T. F. Características fermentativas, microbiológicas e químicas do capim-marandu (Brachiaria brizantha) (Hochst ex e Rich) (Stapf cu. Marandu) ensilado com polpa cítrica peletizada. 2003. 108 f. Dissertação (Mestrado) - Universidade do Estado de São Paulo, São Paulo, 2003.

BRAGA, L. G. T. et al. Valor nutritivo de alguns alimentos para Rã-touro (Rana catesbiana Shaw, 1802) na Fase de Recria. Revista Brasileira Zootecnia, Viçosa, v. 27, n. 2, p. 203-209, 1998.

CASTRO, J. C. et al. Valor nutritivo de alguns alimentos para rãs. Revista Brasileira de Zootecnia, Viçosa, v. 30, p. 605-610, 2001.

DAPKEVICIUS, M. L. E. et al. Lipíds and protein changes during the ensilage of blue whiting (Micromesistius poutassou Risso) by acid and biological methods. Food Chemistry, London, v. 63, n. 1, p. 97-102, 1998.

HOFFMAN, A. The use of coconut cake and fish silage as pig feed in the Seychelles. Tropical Animal Production, [S.1.], v. 6, n. 1, p. 76-77, 1981.

KRIEG, N. R.; HOLT, J. G. (Eds.). Bergey's manual of systematic bacteriology. Baltimore: Williams \& Wilkins, 1984. v. 1, 787 p.

LESSI, L. Ensilajes de pescado en Brasil para la alimentación animal. Manaus: CPTA/INPA, 2004. Disponível em: $\bar{L}$ h aphp134/ cap3.htm>. Acesso em: 11 ago. 2004. 
LIEN, L. V.; PHUNG, N. T.; LY, L. V. Ensiled fish by-products as a protein supplement for fattening pigs. In: WORKSHOP-SEMINAR "MAKING BETTER USE OF LOCAL FEED RESOURCES”, 2000. Resumes... [S.1.]: SAREC/UAF, 2000.

MAIA, W. M. et al. Utilização da fração lipídica de silagens de resíduos de tilápia para utilização em rações para aquicultura. Anais Aquicultura Brasil, [S.1.], v. 2, p. 55-64, 1998.

MARCHI, J. P. O processamento de peixes de água doce. Panorama da Aqüicultura, [S.1.], v. 7, n. 42, p. 38-41, 1997.

MATTERSON, L. D. The metabolizable energy of feed ingredient for chickens: research report, stors. Connecticut: University of Connecticut, 1965.

OTTATI, M.; GUTIERREZ, M.; BELLO, R. Estudio sobre la elaboraticon de ensilado microbiano a partir de pescado proveniente de especies subutilizadas. Archivos Latinoamericanos de Nutricion, [S.1.], v. 40, n. 30, p. 408424, 1990.

PEREIRA, C. A. R. Silagem biológica de peixe: alternativa para o aproveitamento de resíduos de filetamento de peixes. 2002. Dissertação (Mestrado) - Universidade Estadual de Santa Cruz, Ilhéus, 2002.
PIMENTA, M. E. S. G. Fontes e níveis de lipídios em rações de leitões pós-desmame. 2001. Tese (Doutorado em Zootecnia) - Universidade Federal de Lavras, Lavras, 2001.

RAMOS, O. V. et al. Ensayo sobre la alimentacion de la cachama negra (colossoma macropomum) con pescado en acidos organico e inorganico (Fish silage). Boletin Cientifico INPA, [S.1.], v. 2, p. 46-61, 1994.

RIBEIRO, L. P. et al. Efeito do peso e do operador sobre o rendimento de filé em tilápia vermelha Oreochromis spp. Anais da Aquiicultura Brasil, [S.1.], v. 2, p. 773-778, 1998.

SOUZA, M. L. R.; VIEGAS, E. M. M.; KRONKA, S. N. Influência do método de filetagem e categorias do peso sobre o rendimento da carcaça, filé e pele de tilápia do Nilo (Oreochromis niloticus). Revista Brasileira de Zootecnia, Viçosa, v. 1, n. 28, p. 1-6, 1999.

TATTERSON, I. N. Fish silage-preparation, properties and uses. Animal Feed Science and Technology, Amsterdam, n. 7, p. 153-160, 1982.

TATTERSON, I. N.; WINDSOR, M. L. Fish silage. Journal Science Food Agriculture, London, v. 25, p. 369-379, 1974.

TIBBETS, G. W. et al. An evaluation of ensiled waste fish product in swine diets. Journal of Animal Science, Champaign, v. 52, n. 1, p. 93-100, 1981. 